\title{
Are there "dragon-kings" events (i.e. genuine outliers) among extreme avalanches?
}

\author{
C. Ancey ${ }^{1, a}$ \\ École Polytechnique Fédérale de Lausanne, Écublens, 1015 Lausanne, Switzerland
}

Received 23 November 2011 / Received in final form 09 March 2012

Published online 01 May 2012

\begin{abstract}
Predicting the occurrence and spatial extent of extreme avalanches is a longstanding issue. Using field data pooled from various sites within the same mountain range, authors showed that the avalanche size distribution can be described using either an extreme value distribution or a thick-tailed distribution, which implies that although they are much larger than common avalanches, extreme avalanches belong to the same population of events as "small" avalanches. Yet, when looking at historical records of catastrophic avalanches, archives reveal that a few avalanches had features that made them "extraordinary." Applying avalanche-dynamics or statistical models to simulate these past events runs into considerable difficulty since the model parameters or the statical properties are very different from the values usually set to model extreme avalanches. Were these events genuine outliers (also called "dragon-kings")? What were their distinctive features? This paper reviews some of the concepts in use to model extreme events, gives examples of processes that were at play in extreme avalanches, and shows that the concept of dragon-king avalanches is of particular relevance to describing some extreme avalanches.
\end{abstract}

\section{Introduction}

Avalanches are rapid, gravity-driven masses of snow moving down mountain slopes. Like many other weather-related phenomena, snow avalanches can be characterized in terms of frequency of occurrence and magnitude (even though this characterization is far from simple and consensual). The estimation of the magnitude and frequency is all the more important as in land use management in Western countries, risk maps are based on period of return, impact pressure, and spatial extent of avalanches: areas of land are partitioned into zones of different degree of danger depending on the occurrence rate and intensity of historical avalanche events or possible events. Since the early developments of avalanche zoning in Switzerland in the 1950s and 1960s (a procedure that was subsequently imported to most European countries), different approaches have been proposed to estimate the features of infrequent avalanches [1]. Of particular relevance here is the prediction of extreme avalanches, i.e. avalanches

a e-mail: christophe.ancey@epfl.ch 
whose frequency of occurrence is very low and damage potential is very high. Although avalanche-dynamics and statistical models are able to provide decent predictions, there are a number of events, for which the predictive capability of current models is clearly insufficient [2]. Surprisingly enough, the status of these events is seldom if ever discussed. Like for other weather-related processes, these events may be regarded as anomalies or "outliers" that do not call into question the use of models to predict extreme avalanches. Are they really phenomena that are "extra-ordinary" and thus not significant statistically? Do they provide evidence that some events cannot be predicted using current models or even that they are unpredictable? In this respect, February 1999 offers an interesting case study. In Europe, the Alps experienced heavy snowfalls and three major avalanche cycles, with many avalanches hitting villages and roads. In spite of the death toll (69 people were killed in their dwellings or on the road), hazard mapping was regarded as successful since very few avalanches went beyond the predicted limits and damage was less widespread than for earlier catastrophic winters (e.g., in 1954 and 1951) [2,3]. To explain the failure of zoning procedures, two alternatives were put forward: errors could have been made in mapping extreme avalanches (e.g., ignoring past events) or insufficient knowledge of the physical processes (e.g., the motion of the airborne part of the avalanche) could have led to underestimate the avalanche extent. A third track, explored in this paper, is to consider that some extreme avalanches have their own dynamics, which makes them different from other avalanches.

The objective of this paper is to examine why certain past avalanche events were "extra-ordinary", i.e., their features stood out from those exhibited by "ordinary" avalanches. We will see that these extraordinary avalanches can be termed genuine outliers or dragon-kings as suggested by Sornette [4] since they cannot be predicted using standard models or past observations (a more operational definition is given at the end of the introduction), but in spite of this, there is a rationale behind their occurrence, which means that ultimately they may be predictable if a proper computational framework is set up. In this paper, the intent is not to develop new theories or concepts, but to interpret historical records to find out distinctive features in their physical behavior and conditions prior to their release. In this respect, the paper is closer to an opinion paper than a data-based paper. One reason for this is the scarcity of relevant data, which makes the application of simple theories (e.g., univariate extreme value theory) difficult and jeopardize any recourse to more elaborate and realistic theoretical frameworks (e.g., multivariate extreme value theory). Despite this lack of quantitative analysis, I hope that the paper can provide proof of concept and open up the discussion on the relevance of "dragon-kings" in the modeling of extreme avalanches.

Section 2 outlines the current approaches to computing infrequent avalanches and shortly comments on how outliers can be generated or modelled within these approaches. The common belief is that extreme avalanches are caused by extreme snowfalls. While this view holds true for many catastrophic avalanches [2,5-7], there has been ample empirical evidence in recent years that like other multi-component systems, "extra-ordinary" snow avalanches may result from a chain of "ordinary" circumstances (none of them being extreme when considered independently), as shown for instance by the 1999 Péclerey avalanche (see $\S 4.2$ ). Section 3 gives typical examples of extreme avalanches caused by extreme snowfalls, but also shows that heavy precipitation is not an indispensable element to producing extreme events. Section 4 describes mechanisms that best explain the occurrence of extraordinary avalanches through a series of briefly documented historical events.

We have so far avoided the difficult problem of defining an avalanche outlier precisely. As shown in the review paper by Sornette [4], the definition of outliers is likely to be more context-dependent than universal. An outlier is usually defined as an event 
that departs markedly from the rest of events from a statistical standpoint (i.e., the event is distant from the probability distribution that underlies the observed sample). While outlier occurrence is often seen as the hallmark of heavy-tailed distributions (e.g. Zipf's distribution), it may also indicate either that observations were spoiled by measurement errors or that the sample was not identically distributed (i.e, it resulted from a mixture of populations). To distinguish between these various possibilities, Sornette [4] suggests calling "dragon-king outliers" all events that do not belong to the same population as the rest of events. In this respect, providing evidence for dragon-king occurrence amounts to identifying two sub-populations in the observed sample. While this statistical definition of outliers can be successfully applied to many physical systems, it runs into difficulty when one is concerned with snow avalanches. A first difficulty lies in the multivariate nature of avalanches. Summarizing all the avalanche dynamics through a single random variable (e.g., volume, distance traveled by the avalanche, energy) is an oversimplification of reality that may lead to contradictory conclusions depending on the variable selected to capture the bulk dynamics. Then, although avalanche databases are available worldwide, data are mostly of deceptive quality (missing data, significant errors in geographic information, etc.) and it is very difficult to find sites for which avalanche data exist in sufficient number to be exploited statistically. For these reasons, a loose definition of avalanche outlier will be used in the rest of this paper: for a given path, a genuine outlier or dragon-king is an event whose features (volume, impact pressure, distance, etc.) are markedly different from those observed, in particular other rare events.

\section{Modeling major and extreme avalanches}

While scientists have collected field data since the very beginning of the scientific investigations of snow avalanches in the late 19th century, it was not until the 1970s that statistical exploitation of avalanche data was undertaken. Föhn and Meister [8] applied survival analysis and extreme value theory to a sample of 26 events that occurred in the Salezertobel avalanche path (Grisons, Switzerland) from 1950 to 1981. They found that a Gumbel distribution fit fairly well the empirical distribution of runout distance (point of furthest reach). A clear impediment to statistical interpretation is that there are not many avalanche paths for which observations exist in sufficient number (and quality). To get round this difficult, Lied and Bakkehøi [9] assumed a regional homogeneity in the avalanche behavior for a given mountain range, which allowed them to pool the data from various paths in a common database. Then, using regression techniques, they obtained the relation between the runout distance and various key variables of the path profile. When applied to practical cases, this method has the disadvantage of regarding the runout distance as fixed for a given path whereas it is likely to be a random variable that varies from one event to another one ${ }^{1}$ Elaborating on this method, McClung $[10,11]$ applied extreme value theory to (scaled) runout distances. In particular, he showed that when scaled by a characteristic length, the runout distance $x_{\text {stop }}$ has a statistical distribution that can be described by a Gumbel law. More recently, Keylock [12] applied the peakover-threshold method to a runout-distance sample including 199 avalanche events in Iceland and found that this sample was properly described by a Pareto distribution with a negative shape exponent $\xi=-0.614$; this finding implies that there is an upper bound in the statistical distribution of scaled runout distances. Other authors

\footnotetext{
${ }^{1}$ In fact, this is partially true since a premise of the underlying statistical model is that the residuals from the linear regression model are normally distributed, which allows for some randomness in the runout distribution.
} 
focused on different variables to study the statistical properties of snow avalanches. For instance, Birkeland and Landry [13] and Faillettaz et al. [14] considered the size of the start zone and found that the size distribution is characterized by a power law behavior (with an exponent ranging from -0.63 to -1.2 ); both McClung [15] and Bair et al. [16] focused on the slab thickness in the start zone and found that the slab thickness is either log-normally or Fréchet distributed. None of these studies reported the existence of outliers.

An alternative to statistical models is given by the deterministic approach in which the avalanche features are deduced by solving the mass and momentum balance equations [17]. Avalanche-dynamics models usually introduce a friction law, which describes the avalanche/ground interaction as well as energy dissipation (inside the avalanche). In most models, this law includes empirical frictional parameters, which have been fitted from field observations [18-20]. To compute long-return-period avalanches, engineering methods such as the Swiss guidelines suggest default values of the frictional parameters and assume that the period of return of the avalanche is that of the snow depth increase over the last three days preceding the release [21]. Within this computational framework, avalanche outliers may be caused by exceptional snowfalls; they may also arise from strong nonlinearities in the solutions to the governing equations. For instance, if we consider an S-shaped avalanche path, i.e., a path whose longitudinal profile exhibits a plateau area with low inclination, avalanches must have sufficient energy to cross the plateau area; there is thus a threshold effect in the distribution of runout distances between the avalanches that come to a halt on the plateau and those which cross it and continue their descent.

Another approach has recently emerged: the so-called "conceptual approach" ${ }^{2}$ combines statistical and deterministic tools. From avalanche-dynamics models, it retains that physical processes can be idealized in the form of mathematical operators that relate input and output variables. From statistics stems the idea that avalanche features such as volume and runout distance are random variables, whose statistical distribution can be derived from stochastic simulations. Within this approach, as stated by Meunier and Ancey [22], extreme avalanches are expected to have the same behavior as observed events and a priori cannot generate dragon-king events. In principle, it should, however, possible to include additional rules that make the emergence of genuine outliers possible. This approach includes many variants: Monte Carlo simulation [22-25], nonlinear and logistic regressions [26-28], Bayesian inference [20,29-32], which have attracted growing attention in recent years.

\section{Main paradigm}

The traditional view is that most catastrophic avalanches follow the same basic principle: fresh snow accumulates on the slope of a mountain until the gravitational force at the top of the slope exceeds the binding force holding the snow together (this is an oversimplified description of the physical processes, see [33] for further information). A solid slab of the surface layer of snow can then push its way across the underlying layer, resulting in an avalanche. The failure may also arise from a temperature increase, which reduces snow cohesion.

To illustrate this paradigm, let us take the case of an avalanche in the Combe de l'Aiguille in La Foux d'Allos, a ski resort in the southern French Alps (between Digne and Nice). This ski resort (1815 masl) underwent heavy snowfalls from 1 December to 3 December 1976. The totals of snow were approximately $225 \mathrm{~cm}$ within 3 days, but within one night (from 2 to 3 December), snowfalls dropped $150 \mathrm{~cm}$, which is the

\footnotetext{
${ }^{2}$ A term coming from hydrological studies of the watershed response to rainfalls.
} 


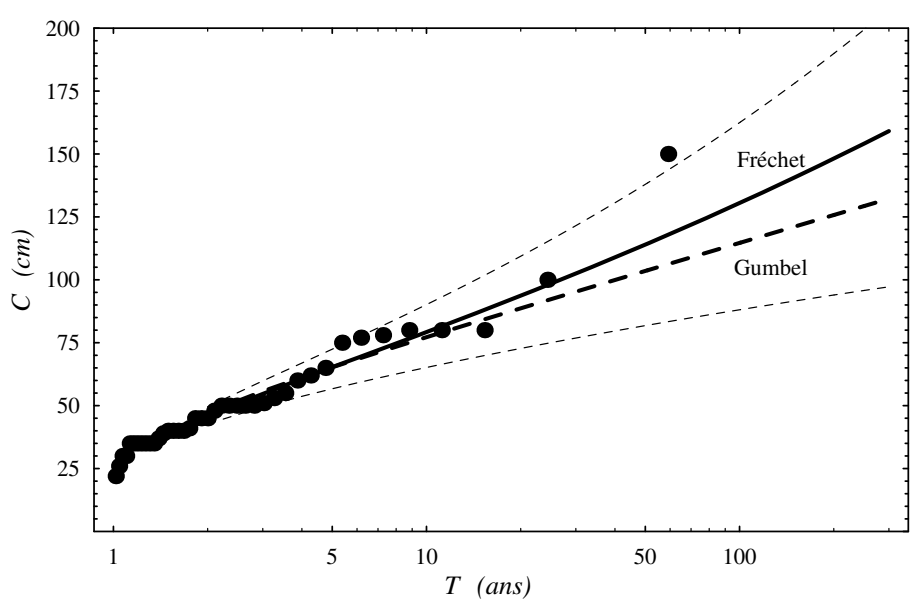

Fig. 1. Return level plot: relation between the daily snowfall and the period of return (only the yearly maxima have been plotted) for la Foux d'Allos (France). The empirical period of return is computed as $T_{i}=n_{a} /(1+i)$ where $i$ is the rank of the snowfall (the sample was ordered in ascending order) and $n_{a}$ is the number of years of the record, here $n_{a}=42 \mathrm{yr}$ (from 1968 to 2009) [34]. The solid line is the Fréchet distribution adjusted on the data using the likelihood maximum technique [34]: $S=\mu-\sigma\left(1-\ln \left(-\ln \left(1-T^{-1}\right)\right)^{-\xi}\right) / \xi$ with $\xi=0.10$, $\mu=40.4 \mathrm{~cm}$, and $\sigma=15.3 \mathrm{~cm}$; the standard errors are, respectively, $0.10,2.62$, and 1.95 . The thin dashed lines represent the $95 \%$ confidence interval. The thick dashed line is the Gumbel distribution $S=\mu-\sigma\left(\ln \left(-\ln \left(1-T^{-1}\right)\right)\right.$ with $\mu=41.3 \mathrm{~cm}$ and $\sigma=15.9 \mathrm{~cm}$.

record for this ski resort and one of the highest values ever recorded in the French Alps. During the snowfalls, stormy winds from the South caused intense drifting so that huge snow accumulations formed on the lee slopes. A tremendous avalanche released as a result of snow accumulation and destroyed 11 out of the 19 pylons of the newly built cable car. As shown by Fig. 1, the 3 December 1976 snowfall clearly stands out from other snowfalls. The 1976 snowfall was a meteorological outlier, which also caused the largest avalanche in the Combe de l'Aiguille in terms of snow volume and damage.

Another historical example is given by the avalanches that occurred in late March 1914 in Chamonix-Mont-Blanc (France). Winter 1913-1914 was cold and dry, with scarce snowfalls over the Alps until early March 1914. After a mild spell, the temperatures dropped again in mid March and snow fell intermittently; on 25 and 26 March 1914, the snowfall intensity increased significantly. In Chamonix town (1050 m asl), the total amount was $90 \mathrm{~cm}$ within 2 days (as against $130 \mathrm{~cm}$ from March 15 to 26 March 26). In the upper part of the Chamonix valley, $200 \mathrm{~cm}$ of snow were observed from 25 to 26 March (as against $265 \mathrm{~cm}$ from 15 to $26 \mathrm{March}$ ). For Chamonix town, the period of return was estimated at $100 \mathrm{yr}$ for the 2-day snowfalls. In contrast, for the upper Chamonix valley, the period of return was much longer than $100 \mathrm{yr}$ for the 2-day snowfalls (an extrapolation of the extreme-value distribution fit on the Le Tour data gives an estimate of $1500 \mathrm{yr}$ !). These snowfalls caused huge avalanches that swept through the valley, causing substantial damage to forests and dwellings. One particular feature of this event was not only the intensity of the snowfalls, but also the number of extreme avalanches triggered the same day and their spatial extent.

Extreme avalanches often result from heavy snowfalls, but they may also be the outcome of an unfortunate chain of circumstances. In pathological cases, small snowfalls can produce extreme avalanches (in terms of the distance traveled by the avalanche). On 23 February 1996, a 16-cm snowfall was sufficient to release a 


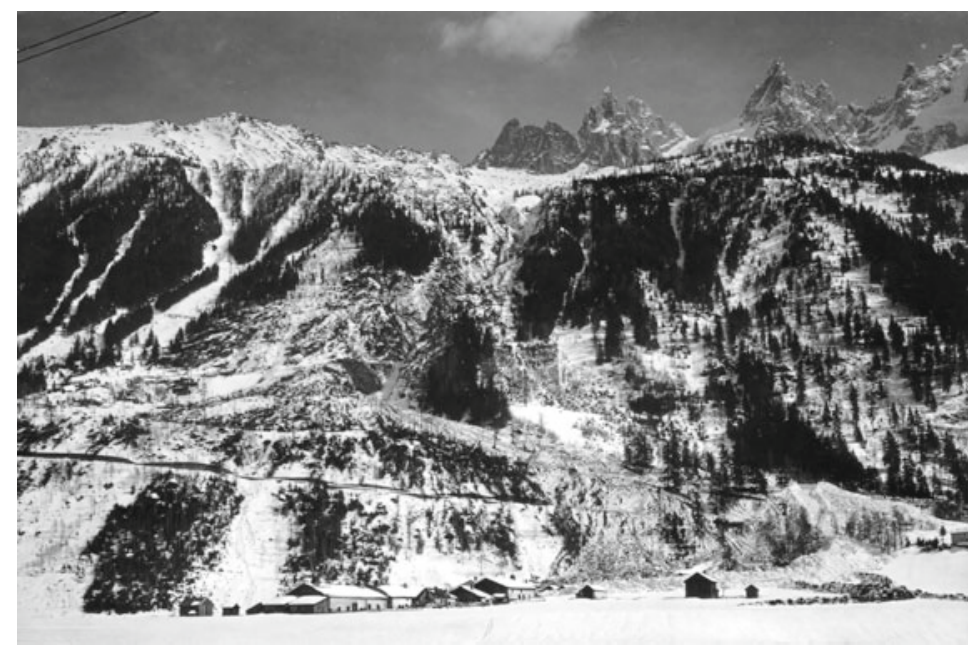

Fig. 2. The forest above Chamonix was destroyed by the numerous avalanches that occurred on 26 March 1914. Photography taken by G. Tairraz on 27 March 1914 (courtesy of RTM Haute-Savoie).

major avalanche that killed one skier in Val-d'Isère on a cross-country skiing track [35]. Except for the latent snow instability, no meteorological factor (e.g., blowing snow or mild spell) could explain the exceptional character of the avalanche. On 9 February 1999, an avalanche occurred in the Péclerey avalanche path above Montroc in the upper Chamonix valley. The avalanche killed 12 people in their houses and was regarded as an extreme event (period of return estimated at $150 \mathrm{yr}$ ). This avalanche resulted from heavy snowfalls from 5 to 9 February, which brought $178 \mathrm{~cm}$ in Montroc $(1400 \mathrm{~m}$ asl $)$. Although this precipitation was intense, it was not exceptional as the period of return was approximately $5 \mathrm{yr}$ [36]; aggravating circumstances that can explain the exceptional character of this avalanche include blowing snow, cold temperature, and the weather conditions prior to February 1999, which contributed to a poor snowpack consolidation (with formation of loose snow at the base of the snow cover) $[36,37]$.

Avalanche outliers are not always the consequence of extreme meteorological conditions. It is thus worthwhile analyzing documented avalanche events to unravel the underlying processes. Here, four main processes are suggested to explain outlier occurrence: change in bed path roughness $(\S 4.1)$, trajectory switch $(\S 4.2)$, diversion by former deposits $(\S 4.3)$, and self-induced deforestation $(\S 4.4)$. This description is not comprehensive; for instance, processes such as snow entrainment are of paramount importance to explain the extent of major avalanches $[38,39]$. Note that on most occasions, the exceptional nature of avalanche outliers results from the combination of several processes rather than a sole process.

\section{Extreme avalanches}

\subsection{Change in the path roughness}

Path roughness is one of the key factors that control energy dissipation in avalanches. Usually, when sufficiently thick, the snowpack flattens out the ground irregularities, which reduces the flow resistance exerted by the bottom. When the avalanche path 


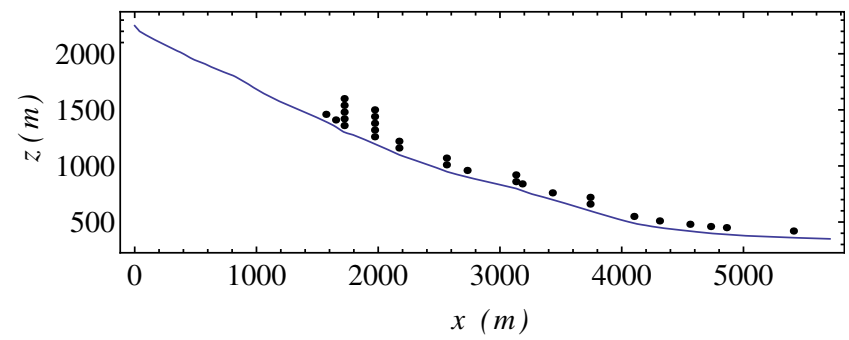

Fig. 3. Profile of the avalanche path (solid line) along the Saint-Clément stream. The dots represent the points of arrest of avalanches recorded in the French avalanche database.

follows the bed of a mountain stream, obstacles such as blocks, steps, and kinks may increase flow resistance significantly. During normal winters, the snowpack is not sufficiently thick to fill the gaps and smooth the path. However, when several avalanches occurred within a short length of time, the avalanche deposits can progressively fill the gaps and reduce flow resistance. This filling and smoothing process may also occur with a single avalanche of very large volume.

An example is given by the site of Pointe de la Grande Journée (2460 masl) above Albertville (Savoie, France) and the 3 March 1923 avalanche. Let us start with the meteorological conditions at that time: 1922 was a very wet year in the Alps, with annual precipitation totals that could be as high as 3 times the average values. From 1 Nov. 1922 to 15 March 1923, the amount of snow in Moûtiers ( $480 \mathrm{~m}$ asl) was $1023 \mathrm{~cm}$ (as against $728 \mathrm{~cm}$ on average) [40]. During the night from 2 March to $3 \mathrm{March}$, one or several avalanches released from the vast western slopes of la Grande Journée and converged toward a canyon draining the Saint-Clément watershed (the canyon entrance is at an elevation of $1700 \mathrm{~m}$ ). Although surrounded by steep slopes, the canyon bed is characterized by moderately steep longitudinal slopes ( $44 \%$ between 1700 and $900 \mathrm{~m}$ in elevation as against $25 \%$ between 900 and $500 \mathrm{~m}$ ). It is usually covered with large boulders, logs, and debris transported by torrential floods. Mild slope and bed roughness explain why most avalanches come to halt in the canyon without reaching the alluvial fan. At an elevation of $500 \mathrm{~m}$, the canyon widens out and opens onto a vast alluvial fan at shallow slope $(8 \%$ between the top of the alluvial fan and the point of confluence). Figure 3 reports all the events recorded since 1906 in the French avalanche database called Enquête Permanente des Avalanches (EPA). On average, the avalanches came to a halt at an elevation of $932 \mathrm{~m}$ (i.e., a distance of $\bar{x}_{\text {stop }}=2620 \mathrm{~m}$ from the Pointe de la Grande Journée), as seen on Fig. 3, a few avalanches were able to travel very long distances (more than $4 \mathrm{~km}$ ) over moderately steep slopes. The 3 March 1923 avalanche stopped at the foot of the alluvial fan (at an elevation of approximately $360 \mathrm{~m}$ ), i.e. it traveled a long distance (more than $600 \mathrm{~m}$ ) on an unconfined slope, whose inclination never exceeds $10 \%$. Compared to other historical events and with model predictions, this avalanche is really an outlier. For instance, if the Voellmy model is used to compute the runout distance, the friction parameter $\mu$ must be as low as 0.08 whereas the Swiss guidelines give 0.155 as the minimum value for extreme avalanches [21]. The 1923 avalanche was not only remarkable in terms of runout distance, but also in terms of snow volume: with a deposited volume ranging from 1.2 to $2.4 \times 10^{6} \mathrm{~m}^{3}$ (depending on the observer), this avalanche was the largest ever observed in this site (the average deposit volume is $238^{\prime} 000 \mathrm{~m}^{3}$ for this path). This volume was sufficiently large to recalibrate the stream cross-section (eye witnesses indicated that in places, the deposit height reached $40 \mathrm{~m} !)$. 


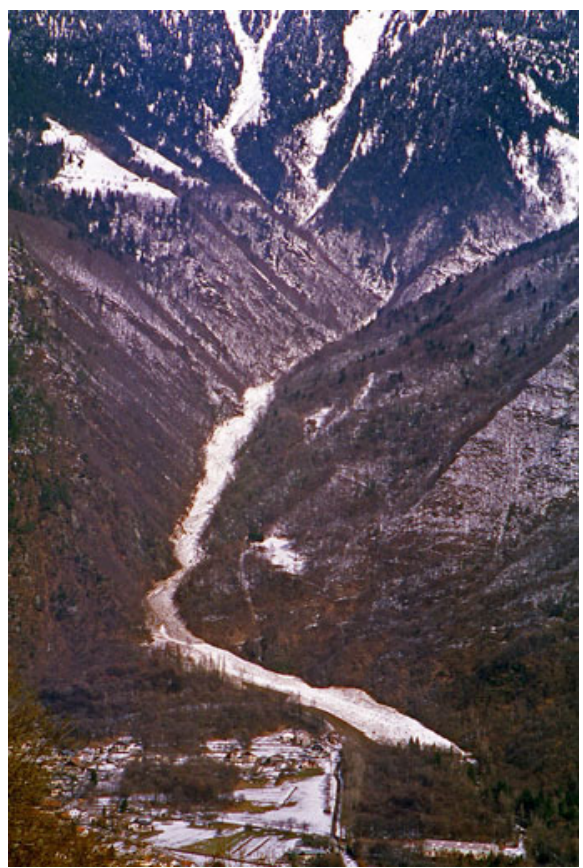

Fig. 4. View of the Saint-Clément watershed and the 1999 avalanche (courtesy of RTM Savoie, photograph by Stéphane Roudnistka).

\subsection{Change in the trajectory}

Avalanche trajectories are usually controlled by topography (inclination, degree of confinement, etc.). This holds particularly for low-speed, friction-dominated avalanches, but is partially true for high-speed avalanches, for which inertial effects can counteract the gravitational forces. With experience, a practitioner can "read" the landscape and predict the avalanches paths, including the runout distance, with some degree of accuracy. In this respect, many avalanche extents are predictable, at least qualitatively. There are, however, some circumstances in which a particular avalanche can switch trajectory, for instance by jumping from one couloir to another one.

An example is given by the Péclerey avalanche in the Chamonix valley, which was already mentioned in $\S 3$. As shown by Fig. 5 , the Péclerey avalanche path refers to the path followed by avalanches released in the north-west face of the Bec du Lachat $(2572 \mathrm{~m})$ and taking the direction of Le Tour, a village at the end of the Chamonix valley. Underneath the start zone (ranging from 2250 to $2570 \mathrm{~m}$ asl), there is a vast area characterized by mild slopes ( $20^{\circ}$ on average) and bumpy surface (due to a rock glacier), which exerts sufficient flow resistance to slow down or even stop most avalanches. At the elevation of $1800 \mathrm{~m}$, there is a break in the slope, with a significant slope increase (from $18^{\circ}$ to $45^{\circ}$ ), which causes the avalanches to accelerate vigorously. When reaching the valley bottom, the avalanches come to a halt on a vast alluvial fan $(1390 \mathrm{~m})$. In February 1999, the avalanche released below the Bec du Lachat took another trajectory: involving dry, low-friction snow, the avalanche reached a sufficiently high velocity to go straight ahead through the bumpy plateau [36]. Although the mild slope caused substantial snow deposition and deceleration, part of the avalanche flux arrived at the slope break and accelerated again, entraining all the snowpack made up of recent snow and old cohesionless snow. When it reached 


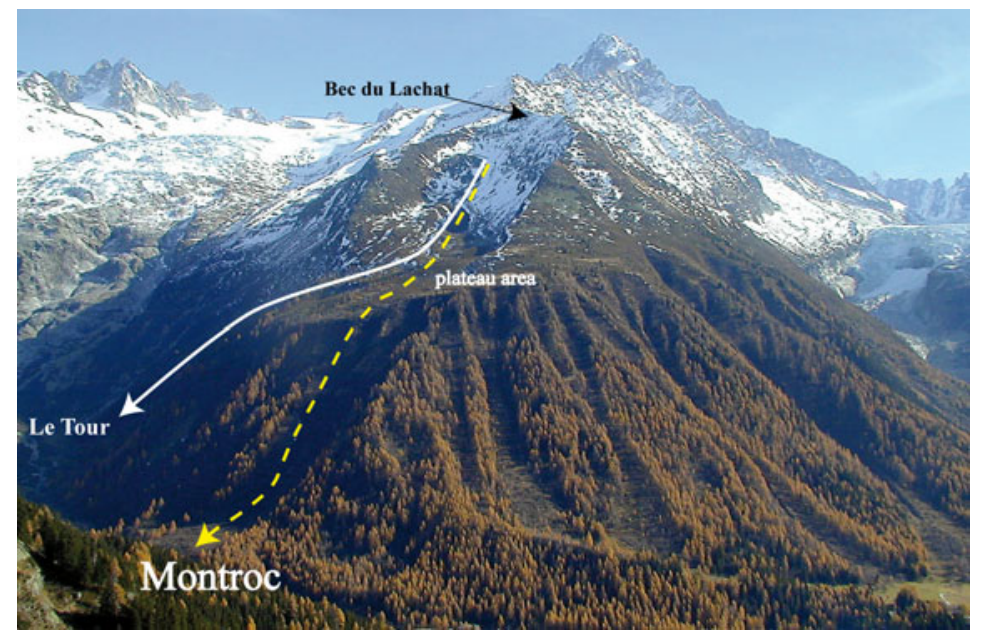

Fig. 5. The Péclerey avalanche path. The solid line represents the usual trajectory followed by avalanches (in direction of Le Tour), while the dashed line stands for the exceptional path taken by the 1999 avalanche (toward Montroc).

the valley bottom, the avalanche was sufficiently vigorous to go up the opposite slope, sweeping through 20 dwellings.

\subsection{Deviation by former deposits}

How an avalanche comes to an arrest is a complex process that depends a great deal on snow rheological behavior, topographical constraints, and avalanche features [41]. High-speed avalanches involving dry snow tend to form widespread and thin deposits, whereas low-speed wet-snow avalanches are prone to form thick and narrow deposits, often exhibiting fingering instabilities, i.e. lobes that can individualize from the rest of the avalanche and take different directions. On most occasions, the behavior of avalanches in their runout phase can be assessed qualitatively, but a few events had characteristics that were barely predictable. This is the case when several avalanches occur within a short period on the same path; their deposits can modify the local topography and divert subsequent avalanches onto other directions. Former avalanche deposits may also obstruct the avalanche path (e.g., a mountain stream) or make avalanche catching dams inefficient (by filling the storage volume upstream of the barriers).

An example is given by the Geschinen avalanches in February 1999 [2]. Geschinen is a small village in the Goms valley (Wallis, Switzerland), which was protected from avalanches by a 4-6-m high barrier. As conspicuous on Fig. 6, three avalanches occurred within 2 days (22 and 23 February 1999). The first one was a high-speed powder snow avalanche, whose deposit crossed the Rhone river (at the bottom of the picture). The second avalanche was a wet snow avalanche, which formed a thick deposit at the top of the alluvial fan, just at the outlet of the couloir. The third avalanche was also a wet snow avalanche, but with a very different behavior since the avalanche traveled a long distance, separated into two branches, and damaged one house (the avalanche barrier's efficiency became low as a result of former deposits). One possible explanation lies in the role played by snowballs and levee formation (lateral deposits). Indeed, the runout distance can be significantly enhanced as a result of levee formation limiting lateral spreading and energy dissipation by 


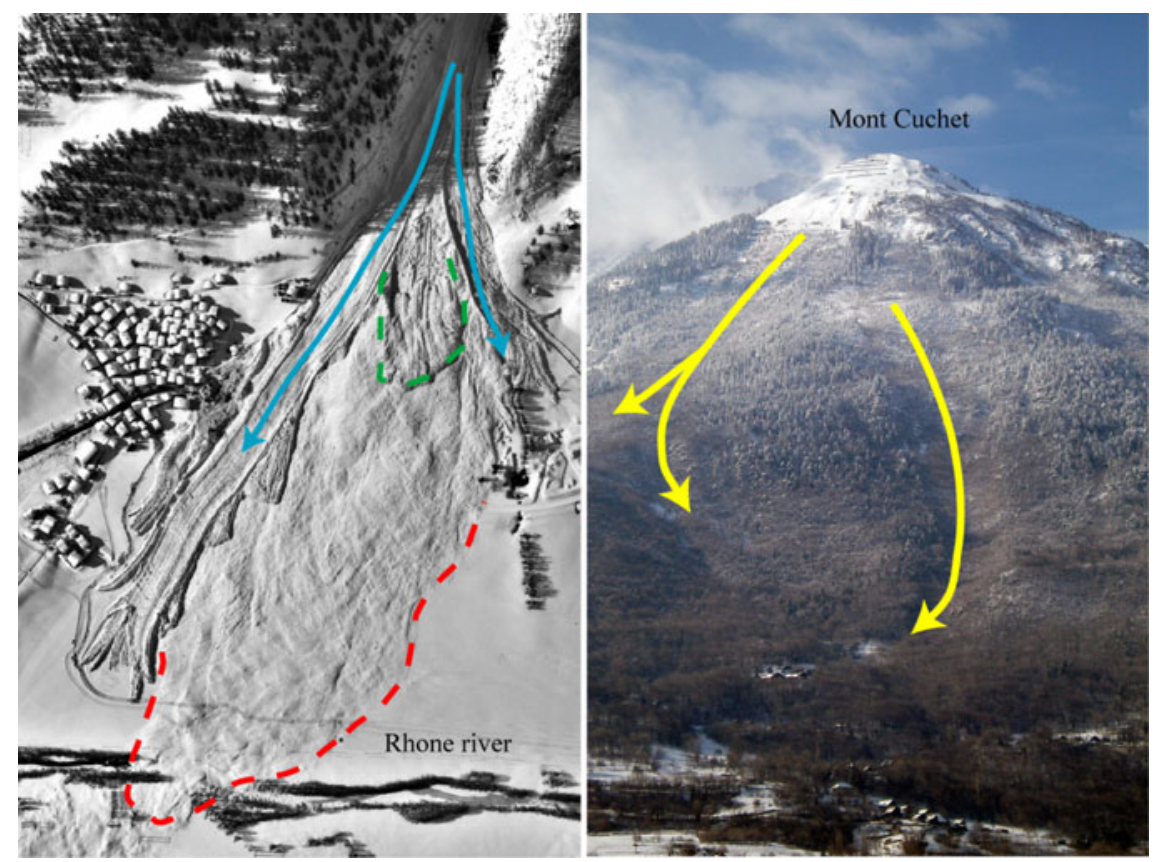

Fig. 6. Left: aerial view of the Geschinen avalanche deposits; the first deposit is delineated by the dashed red curve, the second by the green curve, and the third indicated by blue arrows (courtesy of the Swiss federal topographic service). Right: the Mont Cuchet site; the two avalanche paths through the forest are marked by the arrowed curves.

channelizing the ensuing flow. Usually, dry-snow avalanches do not form snowballs, but since the first avalanche crossed the Trützi lake (located at the base of the starting area) and entrained large volumes of water, the liquid water content in the snowpack was abnormally high and promoted snowball formation in subsequent avalanches.

\subsection{Forest destruction}

Forests are usually an efficient natural barrier against avalanches by hindering their release and, to some degree, increasing flow resistance. For many centuries, it was the only protection of Alpine villages against avalanches, as illustrated by the "Bannwald" ("forbidden forest", literally) protecting Andermatt (Canton of Uri, Switzerland) since the Middle Ages. For this reason, lands located underneath forested areas are often regarded as safe.

There are, however, many historical examples of avalanches that made their own way through dense forests and caused damage. For instance, for a very long time until 1981, inhabitants of Saint-Étienne-de-Cuines in the Maurienne valley (Savoie, France) thought that their dwellings were not threatened by the Mont Cuchet avalanches since the slopes were covered with dense and old forests. As shown by Fig. 6, the snowcapped Mont Cuchet (2102 m asl) emerged $150 \mathrm{~m}$ (in elevation) above forested slopes. In February 1978, after a snow tempest, avalanches were released from the summit and in spite of the low elevation difference between the top and tree line, they acquired sufficient energy to break the trees over a long distance (approximately, $80 \%$ of the forest was destroyed). In late January 1981, heavy snowfalls caused new avalanches, which benefited from the gaps in the forest and swept through the remaining forest, cutting the roads and impacting a few houses (2 people killed). 


\section{Concluding remarks}

We have shown in this paper through a series of historical examples that some events were significantly different from the rest of the events in the same path. Are these "extra-ordinary" events "dragon-kings" (or genuine outliers)? Let us answer this question by looking at the various meanings of outliers.

In the statistical literature, the occurrence of outliers is often related to measurement errors. In the field of avalanches, long-term field surveys are plagued by errors. For instance, if we take the French avalanche database (EPA) which started in the early 1900s, many observation errors stemmed from the topographic map used by the rangers in charge of the survey, which was of very poor resolution until 1976. Elevation errors of $\pm 100 \mathrm{~m}$ were common in the position of points of furthest reach. Deposit volumes were observed to the naked eye, which resulted in tremendous uncertainties in the avalanche size estimation. Missing and censored data are also substantial impediments to statistical analysis. Even with well documented events, thorough analysis reveals that on many occasions, observations were of uneven quality and full of inconsistencies, which may be impossible to clarify, in particular many years after the avalanche occurrence. In spite of all these problems and the current impossibility of providing quantitative evidence, there is clear historical evidence that "extra-ordinary" events occurred.

Outlier occurrence may also indicate that the variables characterizing avalanches are distributed from a heavy-tailed law. The scarcity of avalanche data for a given path has prompted researchers to pool data from various sites to derive empirical distributions. Whereas Birkeland and Landry [13], Faillettaz et al [14] provided evidence of thick tails in the empirical distribution of avalanche size, Keylock [12], who focused on the runout distance, came to an opposite conclusion: the scaled runout distance sample is Weibull-distributed, i.e., extremes are bounded. Note that for earthquakes, when data are pooled from different faults, they collapse onto a well-defined powerlaw distribution, showing no evidence of dragon-king events, whereas when data stem from a single fault, they may exhibit dragon-king events [42]. In this respect, pooling data from various sites may bias the statistical interpretation by smoothing out the tail of the empirical distribution.

A third explanation for outlier occurrence is that the extraordinary events belong to a population that differs from that of the ordinary events. It is difficult to address this question since pinpointing two (or more) sub-populations within an observation sample of low size is delicate. For weather-related variables such as rainfall, observations may not be distributed from a unique law, e.g., in southern France, rainfalls are caused by North-Atlantic and Mediterranean depressions, whose features are very different. In contrast, for snow avalanches, the physical behavior is often the same for major avalanches occurring in the same site. For instance, for the Saint-Clément avalanche paths (see $\S 4.1$ ), all avalanches that arrived onto the alluvial fan were large volume, wet snow avalanches. A priori, there would be no reason for considering several sub-populations for avalanches occurring along the same path. Yet, taking a closer look at the historical examples shows that most extraordinary events shared a common feature: they modified the boundary conditions of the site (by altering roughness, decreasing flow resistance, and/or modifying local topography). The only exception is the Péclerey avalanche (trajectory switch), which is more related to a bifurcation in the avalanche behavior under certain conditions. Both cases (interaction with the boundary conditions, bifurcation) are two of the many scenarios that lead to the emergence of dragon-king outliers according to Sornette [4].

The discussion around the existence of genuine avalanche outliers is not a purely intellectual question. It has many important repercussions in avalanche hazard mapping. For the 1999 Péclerey avalanche, which killed 12 people and destroyed 20 houses 
(see $\S 4.2$ ), predictability was at the core of the debate in the justice court that had to find who was responsible for the disaster. The point is that engineers in charge of risk mapping seek the maximum extent of past events and/or use standard engineering methods (e.g., the Swiss guidelines [21]) to determine the areas exposed to avalanches and for many of them, extreme avalanches are just avalanches that are bigger than their siblings. Realizing that some sites can produce dragon-king avalanches is thus of paramount importance.

I am grateful to the financial support provided by the Competence Center in Environmental Sciences through the research program called Extremes. I thank Stéphane Roudnistka from the Restauration des Terrains en Montagne (RTM) service and Alain Delalune, a former RTM engineer, for their help. I also thank Dr Nicolas Eckert and Dr Jürg Schweizer for their careful reading and the numerous comments that strengthened the paper. The paper is dedicated to Dr Bruno Salm, who opened up the way for modern avalanche-dynamics models.

\section{References}

1. B. Salm, Cold Reg. Sci. Technol. 39, 83 (2004)

2. W.J. Ammann (ed.), Der Lawinenwinter 1999 (Eidgenössisches Institut für Schnee- und Lawinenforschung, Davos, 2000)

3. Bundesamt für Umwelt, Leben mit dem Lawinenrisiko. Die Lehren aus dem Lawinenwinter 1999, Tech. Rep. DIV-7503-D (1999)

4. D. Sornette, Int. J. Terraspace Sci. Eng. 2, 1 (2009)

5. K.W. Birkeland, C.J. Mock, Nat. Hazard 24, 75 (2001)

6. V. Jomelli, C. Delval, D. Grancher, S. Escande, D. Brunstein, B. Hetu, L. Filion, P. Pech, Cold Reg. Sci. Technol. 47, 180 (2007)

7. P. Höller, Nat. Hazard 48, 399 (2009)

8. P. Föhn, R. Meister, in IUFRO/FAO Colloquium on Research on Small Torrential Watersheds (incl. avalanches), vol. 144 (Mitteilung der Forstlichen Bundesversuchsanstalt, Wien, Grenoble, 1982)

9. K. Lied, S. Bakkehøi, J. Glaciol. 26, 165 (1980)

10. D.M. McClung, Can. Geotech. J. 37, 161 (2000)

11. D.M. McClung, Can. Geotech. J. 38, 1254 (2001)

12. C.J. Keylock, Cold Reg. Sci. Technol. 42, 185 (2005)

13. K.W. Birkeland, C.C. Landry, Geophys. Res. Lett. 29, 1 (2002)

14. J. Faillettaz, F. Louchet, J.R. Grasso, Phys. Rev. Lett. 93, 208001 (2004)

15. D.M. McClung, J. Geophys. Res. 114, F01006 (2009)

16. E.H. Bair, J. Dozier, K.W. Birkeland, Geophys. Res. Lett. 35, L23502 (2008)

17. S.P. Pudasaini, K. Hutter, Avalanche Dynamics (Springer, Berlin, 2006)

18. O. Buser, H. Frutiger, J. Glaciol. 26, 121 (1980)

19. C. Ancey, C. Gervasoni, M. Meunier, Cold Reg. Sci. Technol. 39, 161 (2004)

20. C. Ancey, Phil. Trans. Roy. Soc. London A 363, 1529 (2005)

21. B. Salm, A. Burkard, H. Gubler, Berechnung von Fliesslawinen, eine Anleitung für Praktiker mit Beispielen, Tech. Rep. No. 47, institution Eidgenössisches Institut für Schnee- und Lawinenforschung (Davos) (1990)

22. M. Meunier, C. Ancey, J. Glaciol. 50, 268 (2004)

23. C.J. Keylock, D.M. McClung, M.M. Magnússon, J. Glaciol. 45, 303 (1999)

24. M. Barbolini, C.J. Keylock, Nat. Hazard Earth. Sys. Sci. 2, 239 (2002)

25. A.N. Bozhinskiy, Ann. Glaciol. 38, 351 (2004)

26. C. Ancey, M. Meunier, D. Richard, Water Resour. Res. 39, WR01099 (2003)

27. J. Schweizer, C. Mitterer, L. Stoffel, Cold Reg. Sci. Technol. 59, 234 (2009)

28. P. Gauer, K. Kronholm, K. Lied, K. Kristensen, S. Bakkehøi, Cold Reg. Sci. Technol. 62, $42(2010)$ 
29. D. Straub, A. Grêt-Regamey, Cold Reg. Sci. Technol. 46, 192 (2006)

30. N. Eckert, E. Parent, D. Richard, Cold Reg. Sci. Technol. 49, 88 (2007)

31. N. Eckert, E. Parent, M. Naaim, D. Richard, Stoch. Env. Res. Risk Ass. 22, 185 (2008)

32. N. Eckert, M. Naaim, E. Parent, J. Glaciol. 56, 563 (2010)

33. J. Schweizer, J.B. Jamieson, M. Schneebeli, Rev. Geophys. 41, 1016 (2003)

34. S.G. Coles, An Introduction to Statistical Modeling of Extreme Values (Springer, London, 2001)

35. J.F. Meffre, Neige Avalanches 81, 22 (1998)

36. C. Ancey, F. Rapin, E. Martin, C. Coleou, M. Naaim, G. Brunot, Houille Blanche 2000/5, 45 (2000)

37. M. Rousselot, Y. Durand, G. Giraud, L. Mérindol, L. Daniel, J. Glaciol. 56, 758 (2010)

38. C. Ancey, J. Geophys. Res. 109, F01005 (2004)

39. B. Sovilla, S. Margreth, P. Bartelt, Cold Reg. Sci. Technol. 47, 69 (2007)

40. F. Gex, Rev. Geog. Alpine 11, 487 (1923)

41. C. Ancey, Flow on Steep Slope, in Buoyancy Driven Flows, edited by E. Chassignet, C. Cenedese (Cambridge University Press, New York, 2012)

42. V.F. Pisarenko, D. Sornette, M.V. Rodkin, Pure Appl. Geophys. 165, 847 (2008) 